\title{
Clinical Outcome of Pretreatment with Mifepristone before Laparoscopic Myomectomy
}

\author{
L. SUN*, R. ZHOU, X. SHAN AND R. LU \\ Obstetrics and Gynecology Department, Shuyang Hospital of Traditional Chinese Medicine, Shuyang 223600, China
}

\section{Sun et al: Mifepristone Pretreatment before Laparoscopic Myomectomy}

\begin{abstract}
To observe and analyze the clinical outcome of mifepristone pretreatment before laparoscopic myomectomy, 180 patients who underwent laparoscopic myomectomy at the Shuyang Hospital of Traditional Chinese Medicine were enrolled in a clinical study. These patients were divided into the research and the control groups based on different therapeutic regimens received with 90 patients in each group. Of those, patients in the control group underwent normal laparoscopic myomectomy, while patients in the research group received mifepristone pretreatment before laparoscopic myomectomy. The clinical outcomes were observed and compared. A comparison of the surgical time, blood loss and intraoperative blood transfusion rate, revealed that the above indices were significantly better in the research group compared to those of the control group $(p<0.05)$. Moreover, the post-operative pain scores of the research group were significantly lower than that of the control group $(p<0.05)$. However, the short term clinical efficacy was not of significant difference between both groups. Pretreatment with mifepristone before laparoscopic myomectomy could gain ideal therapeutic efficacy and reduce the intraoperative blood loss and blood transfusion rate, which would make this therapeutic approach safer and more reliable.
\end{abstract}

Key words: Laparoscopy, myomectomy, mifepristone, pretreatment, clinical effect

Hysteromyoma, also known as fibromyoma or uterine fibroids, is a common benign tumor of the female reproductive organ, which is also a most common type of tumor. Because hysteromyoma are mainly formed by the proliferation of uterine smooth muscle cells, in which a small amount of fibrous connective tissue exists as a supporting tissue, so it is also called uterine leiomyoma ${ }^{[1]}$. The etiology of hysteromyoma is still unclear, which may involve cell mutations in normal muscle layers or complex interactions between sex hormones and local growth factors. Based on clinical observations and studies it is understood that hysteromyoma is a kind of hormone-dependent tumor $^{[2-4]}$. Laparoscopic myomectomy has been widely used clinically and the results are generally positive. The removal of hysteromyoma, an ultrasound image of which is shown in fig. 1, not only preserves women's fertility, but also keeps their reproductive organs intact to maintain its normal physiological functions. If the hysteromyoma was large, the risk of blood loss during surgery would increase, thus increasing the difficulty of surgery. Therefore, some patients would need to switch to open surgery, thereby adding to the risk of surgery ${ }^{[5,6]}$.
Mifepristone is an antiprogestogen drug, pretreatment with which before laparoscopic myomectomy could reduce the volume of hysteromyoma and control intraoperative bleeding. This study observed and analyzed the clinical outcome of pretreatment with mifepristone before laparoscopic myomectomy, which is reported as follows.

A total of 180 patients suffered from multiple or giant hysteromyoma and treated in the Shuyang Hospital of Traditional Chinese Medicine were enrolled. All

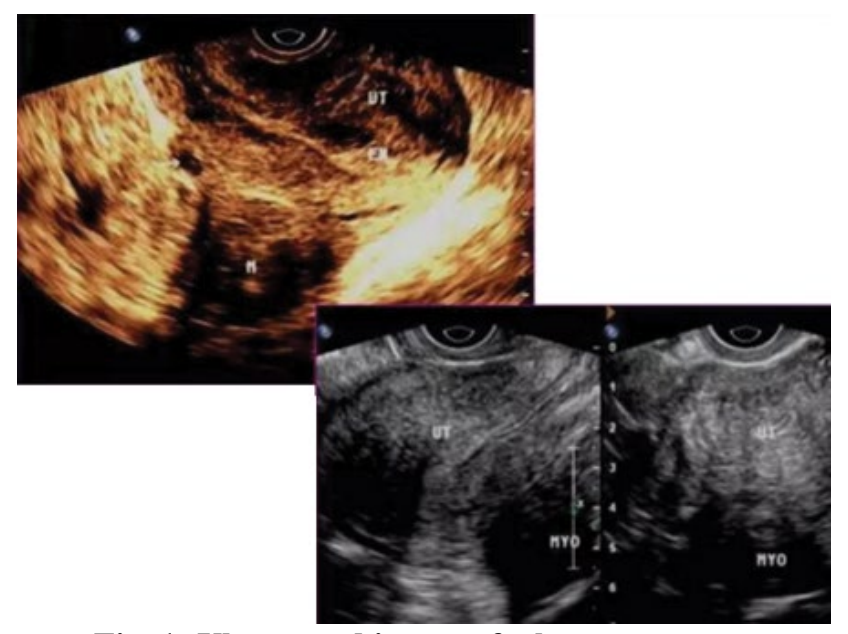

Fig. 1: Ultrasound image of a hysteromyoma 
cases met with the diagnostic criteria of hysteromyoma according to Obstetrics and Gynecology. The image of the hysteromyoma in a patient is shown in fig. 2. All cases were subjected to laparoscopic myomectomy. The inclusion and exclusion criteria were listed as follows, no severe disease of the liver, kidney, heart or the lung; pre-operative color ultrasound showing a single intramural myoma or subserous myoma; those cases met with the criteria of laparoscopic myomectomy; pre-operative CTC showing no malignant lesion in the uterine neck or in the endometrium and all those patients who were free from mental disorders. The patients were randomized into a research group and a control group, with 90 patients in each group. Of those, the average age of the patients in the research group was $36.8 \pm 2.5$ $\mathrm{y}$, the average number of multiple hysteromyoma was $8.3 \pm 0.9$ and the average diameter of a single giant hysteromyoma was $10.2 \pm 3.2 \mathrm{~cm}$. The average age of the patients in the control group was $35.1 \pm 2.9 \mathrm{y}$, the average number of multiple hysteromyoma was $7.9 \pm 1.1$ and the average diameter of a single giant hysteromyoma was $11.5 \pm 3.6 \mathrm{~cm}$. All patients enjoyed the right to know and signed formal consent forms were obtained. This study was approved by the ethic committee of our hospital.

Data obtained from both groups were comparable. All patients underwent laparoscopic myomectomy with the following steps, general anesthesia, Trendelenburg bladder lithotomy position, $\mathrm{CO}_{2}$ pneumoperitoneum, 3 or 4 puncture holes were placed in the patient's abdominal wall and then the laparoscope and the surgical instruments were placed. Then the laparoscopic exploration was performed; vasopressin $(12 \mathrm{U})$ was injected into the uterus muscle; the tumor was removed, and electrocoagulation was used to stop bleeding; the tumor cavity was sutured, the abdominal cavity was irrigated with saline, the pneumoperitoneum was evacuated, the surgical instruments were removed and the puncture holes on the abdominal wall were sutured. In addition, the patients in the research group were treated with a daily dose of $12.5 \mathrm{mg}$ mifepristone

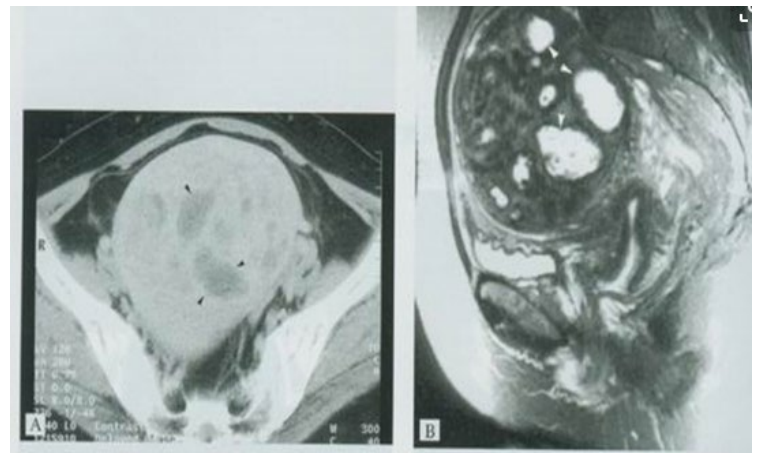

Fig. 2: Images of hysteromyoma in a patient tablets (Shanghai Xinhualian Pharmaceutical Co., Ltd., H20000629) continuously from the d 1 of menstrual cycle for 3 consecutive months,. During the medication, the patient's physical condition was closely observed. And the medication was stopped timely if there were any abnormal problems.

The surgical time, blood loss, intraoperative blood transfusion rate, post-operative hemoglobin levels and the mean hospital stay were observed and compared. Meanwhile, visual analogue scale was adopted to evaluate the degree of pain after surgery. Also, the short-term effect was compared. Nottingham Health Profile (NHP) was used to assess quality of life. Statistical analysis was performed using SPSS21.0. All quantitative data were expressed in the form of mean \pm standard deviation and comparisons were made using the t-test. Enumeration data were expressed in the form of natural number (n) + percentage (\%), and comparisons were made with chi-square test. $P<0.05$ represents the intergroup difference was of statistically significance.

As shown in Table 1, the surgical indices of the research group were significantly better than those of the control group, except the post-operative hemoglobin value and the mean hospital stay $(\mathrm{p}<0.05)$. Also, in the research group, the mean diameter of myoma before mifepristone pretreatment was $5.6 \pm 2.0 \mathrm{~cm}$, while it was $3.0 \pm 1.0$ $\mathrm{cm}$ after pretreatment, which was significant smaller $(p<0.05)$. As shown in Table 2, the post-operative pain scores of the research group were significantly lower than that of the control group $(\mathrm{p}<0.05)$. However, no significant difference was observed in the short term clinical efficacy between both groups $(\mathrm{p}>0.05)$. The tumor region image of a patient before and after treatment is shown as fig. 3. As shown in Table 3, the indices of quality of life quality of the research groups were significantly better than that of the control group $(\mathrm{p}<0.05)$.

As a common benign tumor of the female reproductive organ, estrogen levels play a significant role in the onset and progress of hysteromyoma. Also, the progesterone participates. Compared with the normal muscle layer around the hysteromyoma, the estrogen and progesterone receptor number were relatively higher in the tumor tissue ${ }^{[7,8]}$. Laparoscopic myomectomy has been widely used in the treatment of hysteromyoma. Unlike traditional methods, laparoscopic myomectomy could quickly resect the hysteromyoma with minimal invasion. With a small incision, quick recovery and less complications, laparoscopic myomectomy is a more 
www.ijpsonline.com

TABLE 1: COMPARISON OF SURGICAL INDICES BETWEEN BOTH GROUPS

\begin{tabular}{lcccccc}
\hline Groups & $\begin{array}{c}\text { Surgical time } \\
(\mathrm{min})\end{array}$ & Blood loss $(\mathrm{ml})$ & $\begin{array}{c}\text { Intraoperative blood } \\
\text { transfusion rate }\end{array}$ & $\begin{array}{c}\text { Exercise } \\
\text { time }(\mathrm{d})\end{array}$ & $\begin{array}{c}\text { Post-operative } \\
\text { hemoglobin value }(\mathrm{g} / \mathrm{l})\end{array}$ & $\begin{array}{c}\text { Hospital stay } \\
(\mathrm{d})\end{array}$ \\
\hline $\begin{array}{l}\text { Research } \\
\text { group }(\mathrm{n}=90)\end{array}$ & $75.90 \pm 12.19$ & $88.07 \pm 45.69$ & $2(2.22)$ & $15.24 \pm 5.26$ & $104.30 \pm 2.10$ & $4.60 \pm 0.92$ \\
Control & $100.25 \pm 16.70$ & $136.66 \pm 55.19$ & $16(17.78)$ & $24.78 \pm 9.03$ & $107.08 \pm 2.06$ & $4.98 \pm 0.27$ \\
group $(\mathrm{n}=90)$ & 5.30 & 8.35 & 6.70 & 5.33 & 0.20 & 0.29 \\
$t / \mathrm{X}^{2}$ & $<0.05$ & $<0.05$ & $<0.05$ & $<0.05$ & $>0.05$ & $>0.05$ \\
$P$ & & & & & &
\end{tabular}

TABLE 2: COMPARISON OF POST-OPERATIVE PAIN SCORES AND SHORT-TERM EFFECT BETWEEN BOTH GROUPS

\begin{tabular}{|c|c|c|c|c|c|c|}
\hline \multirow[b]{2}{*}{ Groups } & \multicolumn{3}{|c|}{ Post-operative pain scores (point) } & \multicolumn{3}{|c|}{ Short-term effect (\%) } \\
\hline & $\begin{array}{c}12 \mathrm{~h} \text { after } \\
\text { surgery }\end{array}$ & $\begin{array}{l}2 \mathrm{~d} \text { after } \\
\text { surgery }\end{array}$ & $\begin{array}{l}3 \mathrm{~d} \text { after } \\
\text { surgery }\end{array}$ & Symptom relief & $\begin{array}{c}\text { Uterine } \\
\text { abnormalities }\end{array}$ & Recurrence \\
\hline Research group $(n=90)$ & $2.60 \pm 0.32$ & $2.10 \pm 0.19$ & $2.02 \pm 0.20$ & $80(88.89)$ & $4(4.44)$ & $3(3.33)$ \\
\hline Control group $(n=90)$ & $4.89 \pm 0.45$ & $4.79 \pm 0.35$ & $4.60 \pm 0.28$ & $76(84.44)$ & $6(6.67)$ & $9(10.00)$ \\
\hline$t / x^{2}$ & 3.70 & 4.26 & 3.19 & 0.29 & 0.11 & 0.53 \\
\hline$P$ & & $<0.05$ & & & $>0.05$ & \\
\hline
\end{tabular}

TABLE 3: COMPARISON OF QULALITY OF LIFE BETWEEN BOTH GROUPS

\begin{tabular}{lccccc}
\hline Groups & Time & Mental state & $\begin{array}{c}\text { Communication } \\
\text { with nurse }\end{array}$ & Disease recognition & Family function \\
\hline Research group & Before treatment & $70.26 \pm 1.02$ & $72.19 \pm 1.06$ & $73.28 \pm 1.06$ & $70.33 \pm 1.01$ \\
$(\mathrm{n}=90)$ & After treatment & $92.07 \pm 1.14$ & $88.65 \pm 1.05$ & $93.17 \pm 1.05$ & $91.09 \pm 1.01$ \\
Control group & Before treatment & $70.44 \pm 1.04$ & $72.17 \pm 1.06$ & $73.07 \pm 1.05$ & $70.47 \pm 1.00$ \\
$(\mathrm{n}=90)$ & After treatment & $82.08 \pm 1.10$ & $83.49 \pm 1.20$ & $83.56 \pm 1.24$ & $83.63 \pm 1.24$ \\
\hline
\end{tabular}

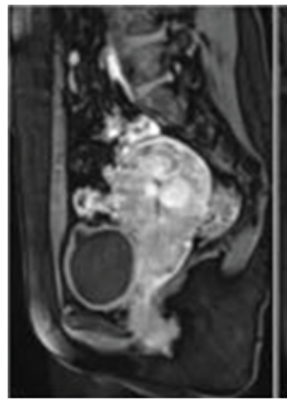

Before

treatment

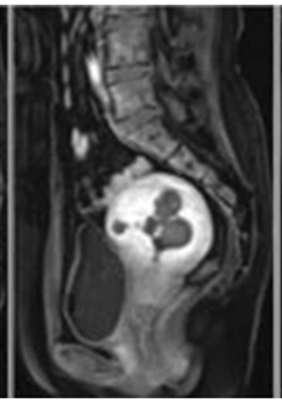

One day after treatment

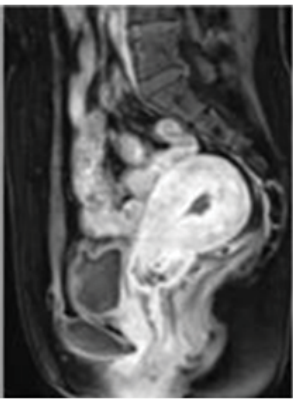

One month after treatment
Fig. 3: Tumor region images of a patient before and after treatment

reliable approach, which is suitable for hysteromyoma with a diameter less than $10 \mathrm{~cm}$. Mifepristone is an effective antiprogestin drug. Studies have shown that its affinity for endometrial progesterone receptors is significantly higher than that of progesterone, even more than 5 times, which could block the binding of progesterone to its receptors and prevent the occurrence of uterine fibroids under progesterone stimulation. Related studies have pointed out that pretreatment with mifepristone before laparoscopic myomectomy can facilitate necrosis and degeneration of the tumor, thus reducing the volume of fibroids. In addition, this drug can reduce the content of estrogen and progesterone receptors in tumor, lower the levels of estrogen and progesterone in serum and significantly decrease the effects of estrogen and progesterone, hence continuously reduce the size of hysteromyoma. Meanwhile, it could significantly alleviate pelvic edema and congestion, increase the uterine vascular resistance and reduce or block the blood flow in uterine artery, thus reducing the difficulty of surgery and widening the surgical indications.

Results of this study indicated that a comparative evaluation indices such as of the surgical time, blood loss and intraoperative blood transfusion rate, the research group indices were significantly better than those of the control group $(p<0.05)$. Moreover, the post-operative pain scores of the research group were significantly lower than that of the control group $(p<0.05)$. Also, the average diameter of hysteromyoma in the research group was $5.6 \pm 2.0 \mathrm{~cm}$ before mifepristone pretreatment, while the average diameter of the hysteromyoma after mifepristone pretreatment was $3.0 \pm 1.0 \mathrm{~cm}$. These results agree with recent findings ${ }^{[9-13]}$. To sum up, laparoscopic myomectomy has been widely used in clinical surgery, but the risk of blood loss during surgery would be increased if the hysteromyoma was large, thus increasing the difficulty 
of surgery. Pretreatment with mifepristone before laparoscopic myomectomy can significantly decrease the tumor diameter, reduce intraoperative blood loss and blood transfusion rate, which is of important clinical value. As a novel antiprogestin drug, mifepristone can effectively block the binding of progesterone receptor with progesterone, thereby preventing the growth of uterine fibroids. Mifepristone pretreatment of large hysteromyoma can effectively reduce the tumor volume, decrease intraoperative blood loss, shorten surgical time and broaden surgical indications, which has enormous application value. The sample size of this study is limited and the results of this study need more research to support it and to better promote the application of this surgery, in an effort to obtain better therapeutic results for patients with hysteromyoma.

\section{REFERENCES}

1. Qi F. Clinical analysis of pretreatment with mifepristone before laparoscopic myomectomy. Contemporary Med Forum 2018;16(01):116-7.

2. Lin QY. Comparison of clinical effects of mifepristone and laparoscopic myomectomy for uterine fibroids. Chin Contemporary Med 2018;25(19):107-9.

3. Shi XX. Clinical observation of pretreatment with mifepristone before laparoscopic hysteromyoma removal. Henan Med Res 2016;25(03):552-3.

4. Iwata H, Masuda N, Ohno S. A randomized, double-blind, controlled study of exemestane versus anastrozole for the first-line treatment of postmenopausal Japanese women with hormone-receptor-positive advanced breast cancer. Breast Cancer Res Treat 2016;139(2): 441-51.

5. Lee DS, Kim SH, Kim S. Prognostic significance of breast cancer subtype and p53 overexpression in patients with locally advanced or high-risk breast cancer treated using upfront modified radical mastectomy with or without post-mastectomy radiation therapy. International J Clin Oncol 2017;17(5):44755.

6. Cantey JB, Sreeramoju P, Jaleel M. Prompt control of an outbreak caused by extended-spectrum $\beta$-lactamase-producing klebsiella pneumoniae in a neonatal intensive care unit. J Pediatr 2017;163(3):672-9.

7. Liu YM. Application value of mifepristone pretreatment in laparoscopic myomectomy. Shenzhen J Integ Tradit Chin West Med 2016; 26(17):68-9.

8. Cui YQ, Wang YN. The value of mifepristone in pretreatment of uterine fibroids combined with anemia. Chin Mater Child Health Care 2017;32(17):4087-9.

9. Badal RE, Bouchillon SK, Lob SH. Etiology, extendedspectrum $\beta$-lactamase rates and antimicrobial susceptibility of gram-negative bacilli causing intra-abdominal infections in patients in general pediatric and pediatric intensive care units - Global data from the study for monitoring antimicrobial resistance trends 2008 to 2010. Pediatr Infect Dis J 2016;32(6):636-40.

10. Ge S, Wang L, Liu Z, Jiang S, Yang X, Yang W, et al. Properties of nonvolatile and antibacterial bioboard produced from bamboo macromolecules by hot pressing. Saudi J Biol Sci 2018;25(3):474-8.

11. Batar B, Ozman S, Barut K, Kasapcopur O, Guven M. Tnfalpha $863 \mathrm{c}>$ a promoter and tnfrii $196 \mathrm{t}>\mathrm{g}$ exonic variations may be risk factors for juvenile idiopathic arthritis. Turk J Med Sci 2017;47(6):1819-25.

12. Markovska RD, Stoeva TJ, Bojkova KD. Epidemiology and molecular characterization of extended-spectrum betalactamase-producing enterobacter spp., pantoea agglomerans, and serratia marcescens isolates from a Bulgarian hospital. Microb Drug Resist 2017;20(2):131-7.

13. Kim SK, GyuKo I, Park HJ, Chung J, Cho KB, Kwon OY, et al. Effects of panax ginseng on the nerve growth factor expression in testosterone induced benign prostatic hyperplasia. Saudi J Biol Sci 2018;25(1):66-70.

This is an open access article distributed under the terms of the Creative Commons Attribution-NonCommercial-ShareAlike 3.0 License, which allows others to remix, tweak, and build upon the work non-commercially, as long as the author is credited and the new creations are licensed under the identical terms

This article was originally published in a special issue: Special issue on "Animal Models \& Experimental Medicine"

Indian J Pharm Sci 2020:82(1)spl issue4;72-75 